\title{
Mitral valve insufficiency and left ventricular remodeling in identical twins
}

\author{
Anders Franco-Cereceda, MD, PhD, Jan Liska, MD, PhD, and Fredrik Bredin, MD, Stockholm, Sweden
}

$\mathrm{H}$ ere we present the outcome of surgical treatment of 2 identical twins with mitral valve regurgitation (MR) and left ventricular (LV) dilatation.

\section{Clinical Summary}

A 52-year-old asymptomatic man (patient 1) presented with a newly detected cardiac murmur at a routine check-up. Further evaluation revealed a large (III-IV/IV) MR and LV dilatation (LV end-diastolic diameter [LVEDD] and LV end-systolic diameter [LVESD] of 62 and $38 \mathrm{~mm}$, respectively). The LV function was preserved, with en ejection fraction (EF) of 60\%. During cardiopulmonary bypass, a large posterior leaflet prolapse with chordal rupture was noted. A quadrangular resection of the P2 segment was performed combined with a sliding plasty and application of a 34-mm Carpentier-Edwards anuloplasty ring. The postoperative course was uneventful, and at 12 months' follow-up, there was a trace $(0-\mathrm{I} / \mathrm{IV})$ of MR, the LVEDD was reduced to $50 \mathrm{~mm}$, the LVESD was reduced to $36 \mathrm{~mm}$, and the EF was maintained (55\%; Figure 1).

Ten months after the operation, the patient's identical twin brother (patient 2) presented at the outpatient clinic. Although asymptomatic, he had a large MR (IV/IV) and a markedly enlarged heart (LVEDD, $80 \mathrm{~mm}$; LVESD, $47 \mathrm{~mm}$ ). The LV function was normal (EF, 60\%). Surgical options were discussed with the patient, including possible benefits with passive containment surgery with the Acorn Cardiac Support Device (CSD) to achieve a rapid and sustained reversed remodeling ${ }^{1}$ in combination with mitral valve surgery. Ethical permission was then obtained from the hospital ethics committee, and written consent was obtained from the patient. The CSD is a mesh-like polyester fabric with bidirectional compliance placed around the heart to reduce wall stress and reshape the dilated heart from a spherical to a more ellipsoidal shape. ${ }^{1}$

The operation was performed with a quadrangular resection of the P2 segment, and a 34-mm Carpentier-Edwards anuloplasty ring was applied because of a large posterior leaflet prolapse and

\footnotetext{
From the Department of Cardiothoracic Surgery and Anaesthesia, Karolinska University Hospital, Stockholm, Sweden.

Supported by the Mats Kleberg Foundation.

Received for publication Jan 19, 2006; revisions received Feb 2, 2006; accepted for publication Feb 7, 2006.

Address for reprints: Anders Franco-Cereceda, MD, PhD, Department of Cardiothoracic Surgery and Anaesthesia, Karolinska University Hospital, S-171 76 Stockholm, Sweden (E-mail: andfra@ki.se).

J Thorac Cardiovasc Surg 2006;131:1400-1

0022-5223/\$32.00

Copyright $\odot 2006$ by The American Association for Thoracic Surgery doi:10.1016/j.jtcvs.2006.02.006
}

chordal rupture. Initially, a 32-mm ring was applied but changed to a 34-mm ring combined with an edge-to-edge stitch to avoid systolic anterior motion of the mitral valve. After an uneventful recovery, the patient was evaluated at 12 months postoperatively, revealing a minimal MR (0-I/IV), a normalized heart size (LVEDD, $52 \mathrm{~mm}$; LVESD, $44 \mathrm{~mm}$ ) and an EF of 50\% (Figure 1).

\section{Discussion}

One of the most common causes of MR necessitating surgical intervention is primary chordal rupture. ${ }^{2}$ The cause of the chordal
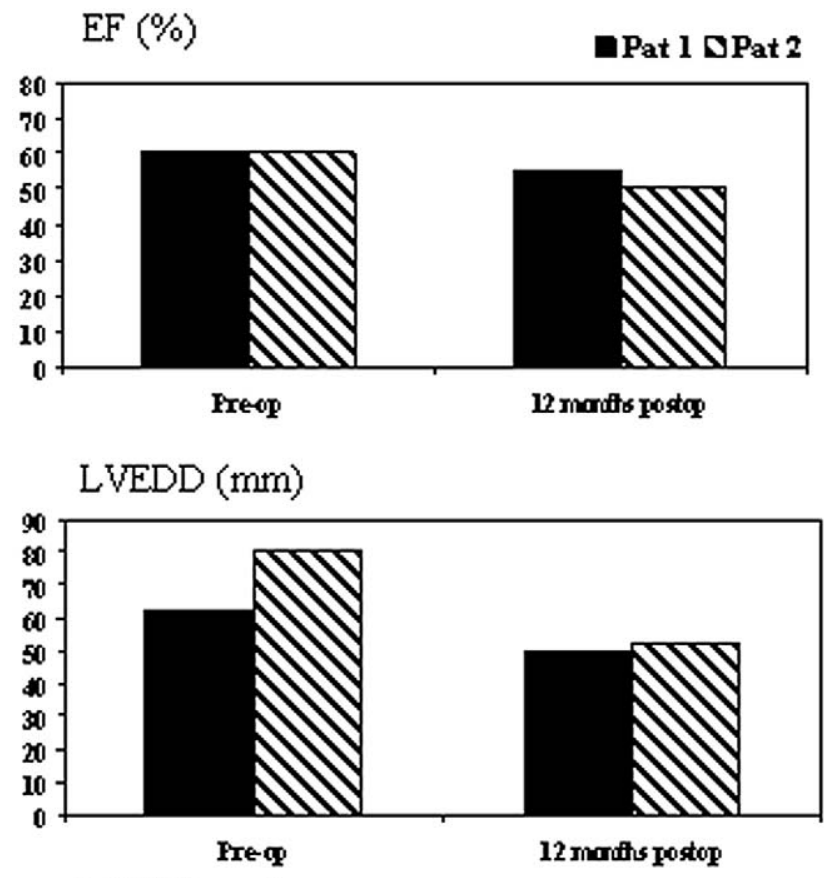

LVESD mm)

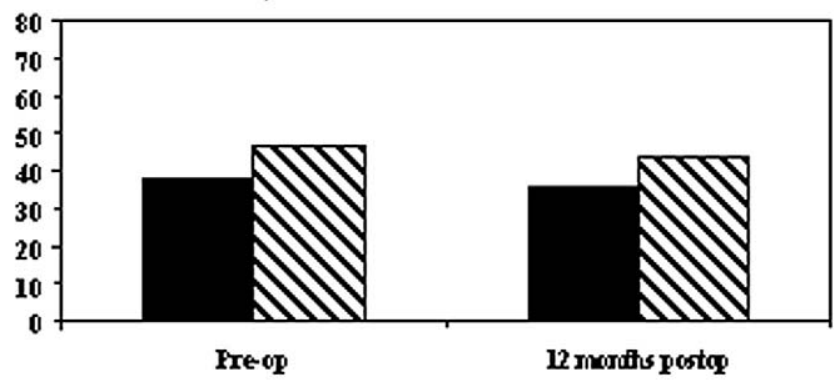

Figure 1. Preoperative and postoperative findings in identical twins subjected to cardiac surgery because of MR and LV dilatation. $E F$, Ejection fraction; $L V E D D$, left ventricular enddiastolic diameter; $L V E S D$, left ventricular end-systolic diameter. 
rupture is usually a myxomatous mitral valve in which the mechanical properties of the chordae are affected.

There are several indications of a genetic link to myxomatous mitral valve disease. Thus patients with autosomal dominant polycystic kidney disease have an increased occurrence of cardiac valve abnormalities, and in patients with Marfan syndrome caused by fibrillin gene defects, myxomatous mitral valve disease is the leading cause of mitral regurgitation. Moreover, a high frequency of the angiotensin-converting enzyme II genotype has been demonstrated in myxomatous mitral valve disease, and a gene associated with the disease has been located on $\mathrm{Xq} 28 .^{3}$

The presented patients had remarkably similar morphologic findings, with a large myxomatous valve and posterior leaflet prolapse combined with chordal rupture. Both of the patients, in addition, had an enlargement of the left ventricle. Eliminating the $\mathrm{MR}$, if performed early, will reduce the volume overload, allowing the left ventricle to recover in size and function. The timing of surgical intervention in asymptomatic patients might be difficult, but when the EF decreases to $60 \%$ or less, the LVESD increases to greater than $40 \mathrm{~mm}$, or both, surgical intervention is advocated. ${ }^{4}$

Patient 2 came to surgical intervention almost a year later than patient 1 and was found to have a more severely enlarged heart. In view of the importance of promoting ventricular reversed remodeling and ensuring a reduction of ventricular size to minimize the risk of potential residual functional MR, the CSD was positioned around the heart. Obviously this proved to be most efficient because the heart rapidly decreased in size with maintained LV function. To what extent passive containment operations should be applied more generally in patients with cardiac LV dilatation remains to be established.

\section{References}

1. Konertz WF, Shapland JE, Hotz H, Dusche S, Braun JP, Stantke K, et al. Passive containment and reverse remodelling by a novel textile cardiac support device. Circulation. 2001;104(suppl):I270-5.

2. Hickey AJ, Wicken DEL, Wright JS, Warren BA. Primary (spontaneous) chordal rupture: relation to myxomatous valve disease and mitral valve prolapse. J Am Coll Cardiol. 1985;5:1341-6.

3. Mieno S, Horimoto H, Asada K, Sasaki S. Simultaneous onset of mitral valve regurgitation requiring surgery due to primary chordal rupture in middle aged identical twins. Int J Cardiol. 2005;103:214-6.

4. Carabello BA. Indications for mitral valve surgery. J Cardiovasc Surg. 2004;45:407-18.

\title{
A fibrous membrane causing left ventricular outflow tract stenosis as the result of endocarditis
}

\author{
Anita Pritisanac, MD, Andreas Hannekum, MD, and Helmut Gulbins, MD
}

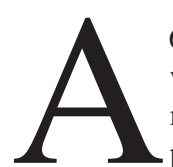

68-year-old man with a history of open heart surgery was admitted to our cardiothoracic surgery department because of fever, dyspnea, and reduced cardiac performance during the last 2 months. Six years ago, the patient underwent biologic aortic valve replacement because of aortic insufficiency, conduit implantation because of aortic aneurysm, and aortocoronary bypasses in our department.

\section{Case Report}

The patient had been admitted to the hospital 4 weeks before with suspected bacteremia. Four teeth were suspected as the focus of infection and were extracted. During that period he showed signs of

From the Department of Cardiothoracic Surgery, University of Ulm, Germany.

Received for publication Nov 3, 2005; accepted for publication Nov 16, 2005.

Address for reprints: Anita Pritisanac, MD, Department of Cardiothoracic Surgery, University Hospital Ulm, Steinhövelstr 9, 89075 Ulm, Germany (E-mail: anita.pritisanac@medizin.uni-ulm.de).

J Thorac Cardiovasc Surg 2006;131:1401-2

$0022-5223 / \$ 32.00$

Copyright $\odot 2006$ by The American Association for Thoracic Surgery doi:10.1016/j.jtcvs.2005.11.057 infection. Along with elevated temperatures blood cultures were drawn and revealed Streptococcus oralis. Transthoracic echocardiography showed no pathologic findings. Cardiac auscultation was repeatedly without pathologic murmurs. Electrocardiography showed no new pathologic findings and no signs of myocardial ischemia. The maximum temperature was $37.9^{\circ} \mathrm{C}$. Laboratory investigations showed leukocytosis (17.000 Giga/L). C-reactive protein was $27 \mathrm{mg} / \mathrm{L}$ at maximum and urine analysis turned out to be normal. The chest x-ray showed no pathology. Repeated transesophageal echocardiography showed no vegetations or abscess of the biologic aortic prosthesis, and no paravalvular leakage. The mitral valve was also normal. A slightly impaired motion of all 3 cusps and a peak-to-peak gradient of $60 \mathrm{~mm} \mathrm{Hg}$ were findings of aortic valve stenosis, which had not been documented before. Ejection fraction was $50 \%$, as in the former study. Heart catheterization showed no pathologic findings. Because the clinical condition of the patient worsened without response to medical treatment, a surgical intervention was scheduled.

The suspected leading preoperative pathologic condition was an impaired cusp motility of the aortic prosthesis caused by acute endocarditis of the valve or aortic conduit, probably explaining the new findings of aortic valve stenosis.

In contrast, the intraoperative appearance of the conduit and aortic valve showed no signs of infection. The prosthesis was free of vegetations or abscess; the leaflet anatomy and its function were 